\title{
Immuno-electronmicroscopy of fimbriae-like structures on Bordetella pertussis serotype 1.3
}

\author{
J. H. FREDRIKSEN, E. NAMORK and L. O. FRøHOLM
}

\section{Department of Methodology, National Institute of Public Health, Geitmyrsveien 75, N-0462 Oslo 4, Norway}

\begin{abstract}
Summary. Fimbriae-like filaments were demonstrated on the surface of Bordetella pertussis, serotype 1.3 , by negative staining and electronmicroscopy. Immunoelectronmicroscopy with a monoclonal antibody specific for strains possessing agglutinogen 3, and colloidal gold, gave strong labelling of these structures. However, incubation with adsorbed polyclonal anti-agglutinogen 3 serum gave only weak labelling of the distal parts of the filaments and of the bacterial surface. The different binding patterns of the two antisera suggested that the epitopes involved were dissimilar. Thus, agglutinogen 3 , as defined by conventional adsorbed sera, appeared to be associated with the fimbriae-like structures but was not necessarily identical to the fimbrial subunit protein. The monoclonal antibody, however, was more likely directed against the subunits of the fimbriae-like structures on serotype 1.3 bacteria.
\end{abstract}

\section{Introduction}

Agglutinogens of $B$. pertussis are surface substances, defined serologically, of which agglutinogens 2 and 3 may have a role in bacterial adhesion (Preston, 1985; Robinson et al., 1985; Cowell et al., 1986). These serotype antigens are thus considered to be candidates for inclusion in acellular vaccines (Carter and Preston, 1984; Robinson et al., 1985; Miller, 1986). Based on epidemiological data, it is recommended that whole-cell vaccines should contain the three major agglutinogens, 1,2 and 3 (Preston, 1963; World Health Organization, 1979). The nature of the species-specific antigen, agglutinogen 1 , is not known (Robinson et al., 1985). Some investigators have described both agglutinogens 2 and 3 as fimbriae by immuno-electronmicroscopy with monoclonal antibodies (Ashworth et al., 1982, 1985). The fimbrial nature of agglutinogen 2 seems to be generally accepted, but the nature of agglutinogen 3 is still debatable (Preston, 1985; Cowell et al., 1986; Weiss and Hewlett, 1986). In contrast to the immuno-electronmicroscopic evidence (Ashworth et al., 1985), electronmicroscopy of a large number of serotyped strains revealed no fimbriae on serotype 1.3 strains whereas strains of serotypes 1.2 and 1.2.3 were all fimbriated (Carter and Preston, 1984).

In the present study negatively stained samples of three well-characterised strains possessing agglutinogen 3 were examined by electronmicroscopy. Serotype 1.3 bacteria were also examined by

Received 27 April 1987; revised version accepted 10 Aug. 1987. immuno-electronmicroscopy and gold-labelling with adsorbed anti-agglutinogen 3 serum and a monoclonal antibody specific for strains possessing agglutinogen 3 (Ashworth et al., 1985).

\section{Materials and methods}

\section{Bacteria}

B. pertussis strain M 2 (serotype 1.3) was obtained from Dr N. W. Preston, Pertussis Reference Laboratory, Department of Bacteriology and Virology, University Medical School, Manchester. Strains CN 5476 (serotype 1.3) and 28 (serotype 1.2.3) were obtained from Dr P. Novotny, Department of Bacteriology, Wellcome Research Laboratories, Beckenham, Kent. The strains were stored and cultivated as described previously (Lothe $e t$ al., 1985; Fredriksen et al., 1985, 1987).

\section{Electronmicroscopy}

The bacteria, grown on Bordet-Gengou (BG) plates for $60 \mathrm{~h}$ at $33-34^{\circ} \mathrm{C}$, were suspended in distilled water, centrifuged at $2300 \mathrm{~g}$ for $20 \mathrm{~min}$, washed once and resuspended in distilled water. Bacteria from shaken cultures, grown in a modified Stainer and Scholte medium (Lothe et al., 1985) for $60 \mathrm{~h}$ at $33-34^{\circ} \mathrm{C}$, were harvested by centrifugation, then washed and resuspended as above. Droplets $(5 \mu 1)$ of the suspensions were applied to carbon-filmed grids which had previously been glowdischarged in air (Namork and Johansen, 1982). The grids were blotted almost dry after $1 \mathrm{~min}$ and then stained with a drop of sodium phosphotungstate $0.25 \% \mathrm{w} / \mathrm{v}, p \mathrm{H}$ $7 \cdot 0$, for another $1 \mathrm{~min}$. Electronmicroscopy was performed on a JEM 100B operated at $80 \mathrm{keV}$. Liquid 
nitrogen anti-contaminant devices were in use when examining all specimens.

\section{Sera}

The anti-agglutinogen 3 (factor 3 ) serum was rendered specific for agglutinogen 3 by adsorption of rabbit hyperimmune serum against whole $B$. pertussis cells, strain M 2, with bacteria of heterologous serotype (Fredriksen et al., 1985, 1987). Control (factor 0) serum was made by absorption of the same anti-M 2 serum with autologous cells (i.e., $\mathrm{M}$ 2). This gave a reduction in agglutinating activity from a titre of 1280 to $<5$ (Fredriksen et al., 1987). The monoclonal antibodies AG2A and AG3A (Ashworth et al., 1985), specific for cells possessing agglutinogen 2 and 3 , respectively, were obtained from L. A. E. Ashworth, Public Health Laboratory Service, Centre for Applied Microbiology and Research, Porton Down, Salisbury, Wiltshire. The monoclonal antibodies were of the IgM class and were supplied as culture supernates. In a micro-agglutination assay (Fredriksen et al., 1987) the culture supernates gave a titre of 32 .

\section{Immuno-electronmicroscopy}

Bacterial suspensions were applied to untreated carbon-filmed grids, left for $2 \mathrm{~min}$ and blotted almost dry. Grids were then incubated face down on drops of a suitable antibody dilution, then washed on several drops of $0.1 \mathrm{M}$ ammonium acetate, $p \mathrm{H} 7 \cdot 0$, and blotted almost dry, before incubation with the appropriate gold probe (see below). Finally, after several washings with ammonium acetate buffer, the specimens were stained with sodium phosphotungstate $0 \cdot 25 \% \mathrm{w} / \mathrm{v}, p \mathrm{H} 7 \cdot 0$, for $30 \mathrm{~s}$.

The bacteria were incubated for 2 min with a 1000 fold dilution of the polyclonal sera and for $2 \mathrm{~min}$ with a 10-fold dilution of staphylococcal protein A conjugated to $10-\mathrm{nm}$ colloidal gold particles (Polaron, Bio-Rad, Richmond, VA, USA). When applying the monoclonal sera, the specimens were incubated for $10 \mathrm{~min}$ with an 8fold dilution and incubated for $2 \mathrm{~min}$ with a 10 -fold dilution of goat anti-mouse IgM conjugated to 5-nm gold particles (Janssen Pharmaceutica, Bersee, Belgium). All incubations were at room temperature. The dilutions of sera and gold probes were made in $0.1 \mathrm{M}$ ammonium acetate, $p \mathrm{H} \mathrm{7.0.}$

\section{Results}

Electronmicroscopy of bacteria revealed thin fimbriae-like filaments on all three strains examined. Fig. 1 shows a micrograph of strain $\mathbf{M} 2$, serotype 1.3, from BG plates. The extending structures were short and rigid with an irregular outline, $4.5-5 \mathrm{~nm}$ in width and $100-250 \mathrm{~nm}$ in length. In liquid cultures, the number and length of the filaments were increased. Examinations of the

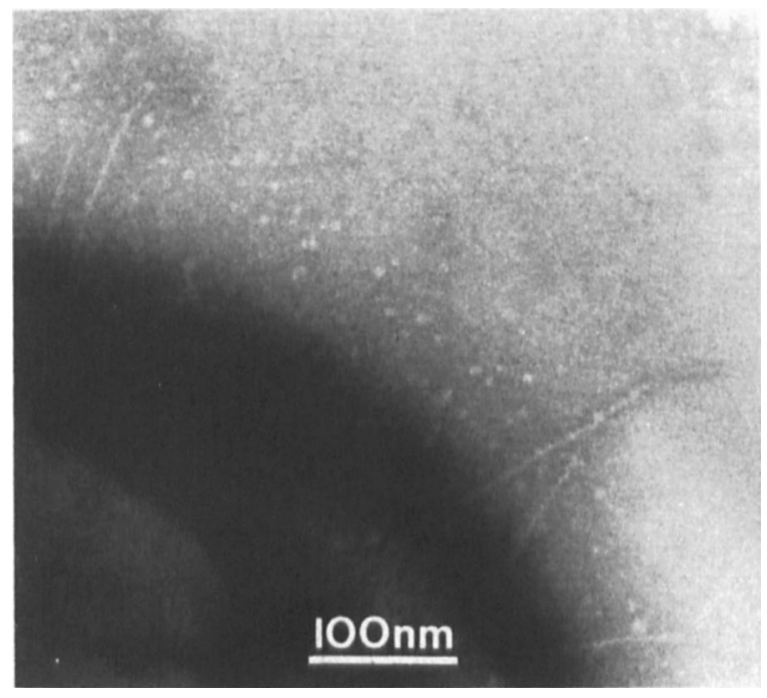

Fig. 1. Electronmicrograph showing fimbriae-like structures on $B$. pertussis strain $\mathrm{M} 2$, serotype 1.3 , grown on $\mathrm{BG}$ agar, negatively-stained with sodium phosphotungstate $0.25 \% \mathrm{w} / \mathrm{v}$, pH $7 \cdot 0(150000 \times)$.

other strains showed that strain CN 5476 (serotype 1.3) had more filaments than strain $M 2$, but less than strain 28 (serotype 1.2.3) (micrographs not shown).

Immuno-electronmicroscopy of strain $\mathbf{M}$ 2, with the monoclonal antibody AG3A gave a clear specific labelling of the fimbriae-like structures (fig. 2c), whereas after incubation with the monoclonal antibody AG2A (fig. 2d), no labelling of these structures was seen. The factor- 3 serum gave weak labelling of the distal parts of the filaments (fig. 2a) and some labelling of the bacterial surface (not shown). Bacteria incubated with factor-0 serum (fig. 2b), gave no specific labelling. After incubation with the monoclonal antibodies, the extending filaments were more difficult to visualise because of antibody binding and, presumably, to other material in the monoclonal preparation (figs. $2 \mathrm{c}$ and $2 d)$. The use of higher concentrations of sera and gold probes or longer incubation times gave higher background labelling. The specificities of the probes were checked by incubating the bacteria with the probes only; no binding was seen.

\section{Discussion}

The serotype-1.3 strains in this study clearly carried fimbriae-like appendages, as did the serotype 1.2.3 strain. The filaments were short, thin and with an irregular outline, which may have been due to partial disintegration. Their diameter $(4 \cdot 5-5 \mathrm{~nm})$ 

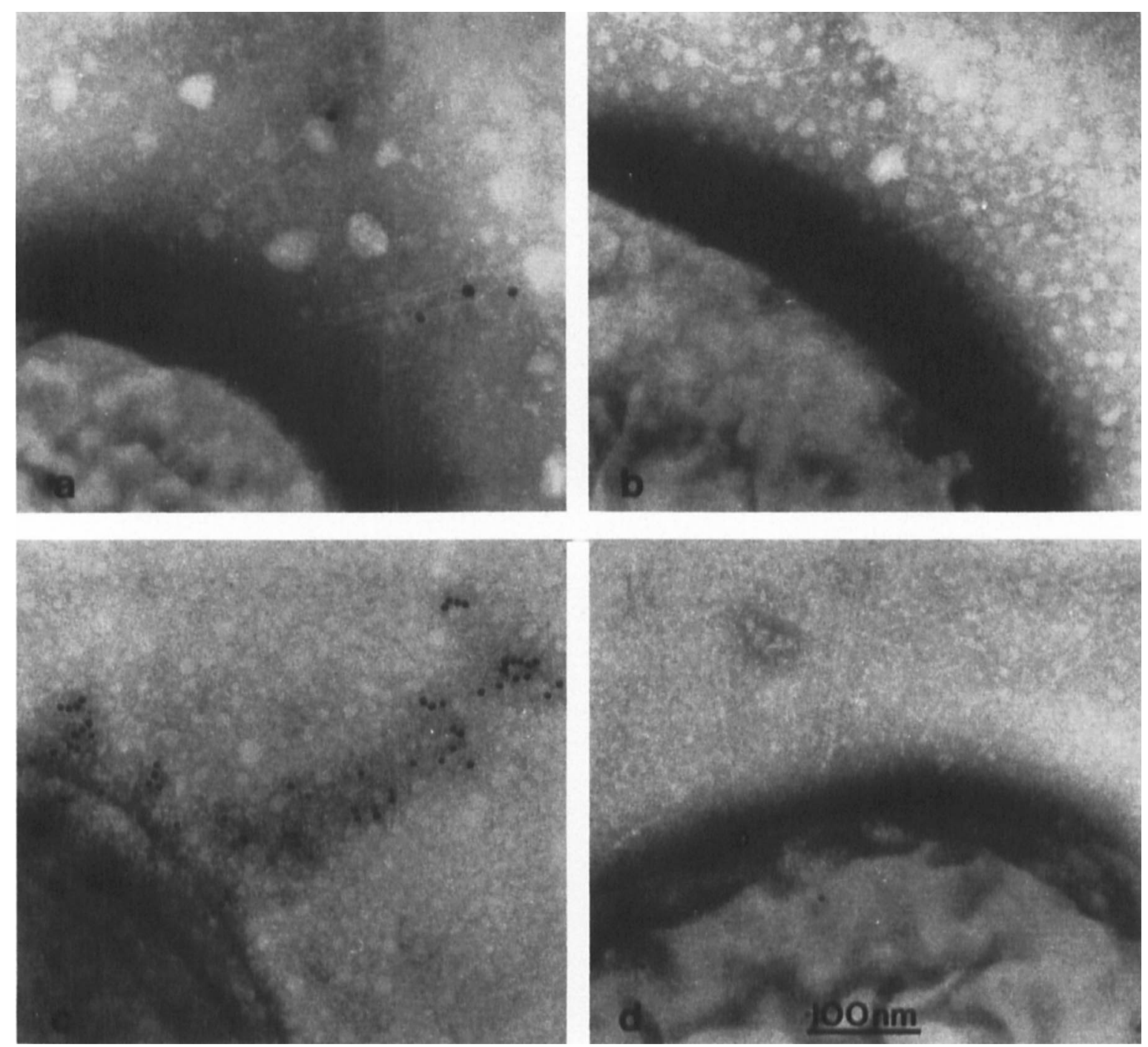

Fig. 2. Immuno-electronmicroscopy of $\boldsymbol{B}$. pertussis strain $\mathbf{M} 2$, serotype 1.3, grown in liquid culture. Bacteria were incubated with anti-agglutinogen 3 serum (a) and factor 0 serum (b) as primary antibodies, then labelled with protein A-gold (10 nm). In (c) and (d) bacteria were incubated with AG3A or AG2A, respectively, then labelled with anti-mouse IgM-gold $(5 \mathrm{~nm}) .(150000 \times)$.

was smaller than that reported for the $B$. pertussis fimbriae (5-6 nm) studied by Steven et al. (1986).

The observation that liquid culture seemed to increase the number and length of the filaments, and that the fimbriae-like filaments on the serotype1.2.3 strain were more numerous, are in accordance with other data (Ashworth et al., 1985). The finding that the serotype-1.3 strains examined by Carter and Preston (1984) did not carry fimbriae-like structures could have been due to the washing procedures used or to the fact that most of their strains were fresh isolates, whereas we used labo- ratory strains. Furthermore, expression of the filaments may have been inhibited by the use of Charcoal Blood Agar by Carter and Preston (1984) or as suggested above, the filaments of serotype-1.3 strains may be particularly fragile. Nevertheless, Carter and Preston (1984) were able to agglutinate serotype-1.3 strains, on which no filaments were seen, with factor 3-specific serum. Thus, their results give strong support to the view that agglutinogen 3 is not synonymous with fimbriaelike structures.

The use of different nomenclatures for $B$. pertussis 
agglutinogens seems to complicate the identification of the serotype antigens (Weiss and Hewlett, 1986). Purified fimbriae from strain 114, which possesses agglutinogen 3 , have been reported not to induce antibodies to agglutinogen 3 . These purified fimbriae are instead stated to represent agglutinogen 6 (Cowell et al., 1986). We have been using the typing schemes of Preston, which does not recognise agglutinogen 6 (Preston et al., 1982). Anti-agglutinogen 6 reagents were not available and thus we have not tested the present strains for agglutinogen 6 properties.

The strong labelling of the fimbriae-like structures on serotype-1.3 strains with the monoclonal antibody AG3A is similar to the picture presented by Ashworth et al. (1985) with the same monoclonal antibody. However, immuno-electronmicroscopy of strain M 2 with polyclonal anti-agglutinogen 3

\section{REFERENCES}

Ashworth L A E, Dowsett A B, Irons L I, Robinson A 1985 The location of surface antigens of Bordetella pertussis by immuno-electronmicroscopy. Developments in Biological Standardization 61:143-151.

Ashworth L A E, Irons L I, Dowsett A B 1982 Antigenic relationship between serotype-specific agglutinogen and fimbriae of Bordetella pertussis. Infection and Immunity 37:1278-1281.

Carter E J, Preston N W 1984 Association between Bordetella pertussis agglutinogen 2 and fimbriae. Journal of Medical Microbiology 18:87-94.

Cowell J L, Urisu A, Zhang J M, Steven A C, Manclark C R 1986 The filamentous hemagglutinin and fimbriae of Bordetella pertussis: Properties and roles in attachment. In: Leive L (ed) Microbiology-1986. American Society for Microbiology, Washington D.C., pp 55-58.

Fredriksen J H, Frøholm L O, Kjennerud U 1987 The specificity of antisera against Bordetella pertussis examined by bacterial agglutination. Acta Pathologica, Microbiologica et Immunologica Scandinavica, Sect. B 95: 363-369.

Fredriksen, J H, Frøholm L O, Paulsen B S 1985 Purification and preliminary characterization of agglutinogen 3 from Bordetella pertussis. Developments in Biological Standardization 61 : 187-196.

Lothe R A, Frøholm L O, Westre G, Kjennerud U 1985 Stainer serum, did not show such strong binding to one single visible structure. This may suggest that there are differences in the specificities of the polyclonal anti-agglutinogen 3 serum and the AG3A monoclonal antibody. We believe AG3A to be specific for an epitope of the fimbriae-like structures found on cells of serotypes 1.3 and 1.2.3, and we suggest that our anti-agglutinogen 3 serum has its main activity directed towards other antigenic determinants, probably associated with both the fimbriaelike structures and the cell body. The different binding patterns indicate that the term agglutinogen 3 covers more than one structure; or, possibly, that not all agglutinogen 3 is assembled into fimbriae-like structures.

We thank Drs N. W. Preston and P. Novotny for providing strains, and L. A. E. Ashworth for the monoclonal antibodies.

and Scholte's pertussis medium with an alternative buffer. Journal of Biological Standardization 13:129-134.

Miller E 1986 Progress towards a new pertussis vaccine. British Medical Journal 292:1348-1350.

Namork E, Johansen B V 1982 Surface activation of carbon film supports for biological electron microscopy. Ultramicroscopy 7:321-330.

Preston N W 1963 Type-specific immunity against whoopingcough. British Medical Journal 2:724-726.

Preston N W 1985 Essential immunogens in human pertussis: The role of fimbriae. Developments in Biological Standardization 61 : 137-141.

Preston N W, Surapatana N, Carter E J 1982 A reappraisal of serotype factors 4, 5 and 6 of Bordetella pertussis. Journal of Hygiene 88: 39-46.

Robinson A, Irons L I, Ashworth L A E 1985 Pertussis vaccine : present status and future prospects. Vaccine 3: 11-22.

Steven A C, Bisher M E, Trus B L, Thomas D, Zhang J M, Cowell J L 1986 Helical structure of Bordetella pertussis fimbriae. Journal of Bacteriology 167:968-974.

Weiss A A, Hewlett E L 1986 Virulence factors of Bordetella pertussis. Annual Review of Microbiology 40:661-686.

World Health Organization, Expert Committee on Biological Standardization 1979 Requirements for pertussis vaccine. Thirtieth Report. WHO, Technical Report Series, no. 638, pp 60-80. 